\title{
Perspectives on Neuroradiology Medical Expert Testimony: Fact and Fiction
}

\author{
(DD.M. Yousem, (D) G.H. Zoarski, (D)A.S. Mark, and DE.S. Schwartz
}

\begin{abstract}
SUMMARY: There are numerous misconceptions about serving as a medical malpractice expert witness. By maintaining an objective perspective based in the unbiased interpretation of the images provided (for both sides of the conflict), one can best serve society as a whole. Most cases for which a neuroradiology expert is recruited are the following: 1) not with the radiologist as a defendant, 2) resolved without court testimony, and 3) short-lived if frivolous. One can learn much about medicine, our nonradiology colleagues, and the litigation process by participating as an expert witness.
\end{abstract}

ABBREVIATION: ACR = American College of Radiology

$\mathrm{T}$

his article provides multiple perspectives on the issues of serv-

ing as a medicolegal expert witness from the standpoint of a diagnostic neuroradiologist in academia (D.M.Y.), interventional neuroradiologist (G.H.Z.), private practice neuroradiologist (A.S.M.), and pediatric neuroradiologist (E.S.S.). When serving as an expert witness at a trial, one may be required to establish 3 of the 4 components of a legitimate malpractice case: 1 ) the standard of care for practice; 2 ) causation, ie, that the negligent act led to the damages; and 3) the damages leading from the negligent act. The fourth component, "duty," in which a doctor-patient relationship is established, is rarely brought up outside the anonymous "curbside consult" or teleradiology preliminary reports. The American College of Radiology (ACR) has published practice parameters for expert witnesses regarding qualifications, responsibilities, and requisites ${ }^{1}$ and recommends that its members sign an "ACR Expert Witness Affirmation Statement," which describes the principles of appropriate behavior as an expert witness. ${ }^{2}$

\footnotetext{
Received May 21, 2018; accepted after revision June 21.

From the Department of Radiology (D.M.Y.), Division of Neuroradiology, Johns Hopkins Medical Institution, Baltimore, Maryland; Department of Neurointerventional Surgery (G.H.Z.), Christiana Care Health System, Newark, Delaware; Bethesda MRI and CT (A.S.M.), Rockville, Maryland; and Department of Radiology (E.S.S.), Division of Neuroradiology, Perelman School of Medicine and the Children's Hospital of Philadelphia, Philadelphia, Pennsylvania.

Dr Yousem also wishes to disclose that he met his wife serving as an expert witness for her.

Please address correspondence to David M. Yousem, MD, MBA, Johns Hopkins Medical Institution, 600 North Wolfe St, Phipps B100F, Baltimore, Maryland 21287; e-mail: dyousem1@jhu.edu

http://dx.doi.org/10.3174/ajnr.A5779
}

\section{How Are You Selected to Be an Expert Witness?}

Most neuroradiologists have the opportunity to serve as expert witnesses. Two previous publications noted that of American Society of Neuroradiology member respondents to an on-line survey, $43.6 \%-44.1 \%$ had served as expert witnesses in neuroradiology, including nearly $71 \%$ of those older than 50 years of age. ${ }^{3,4}$ However, most $(59.4 \%)$ of those who stated they had served as expert witnesses had served in fewer than 5 cases. ${ }^{4}$

Before assuming the position of Director of Neuroradiology at Johns Hopkins in 1998, I had never served as an expert witness. However, shortly after arriving at Hopkins, I began to get calls from malpractice lawyers searching for neuroradiology expert witnesses. I assumed that they Googled "Johns Hopkins Neuroradiology" or were referred via the Hopkins hospital operator ("Can you connect me to the Director of Neuroradiology, please?"). I have no idea why I became "targeted" as a reviewer.

During the past 20 years, I have now served in depositions and/or trial testimony on 50 medical malpractice cases, 1 capital murder trial, 5 personal injury cases ( 3 motor vehicle collisions, 1 carbon monoxide in the home, and 1 mold in the workplace), and 5 product liability trials ( 3 from the pharmaceutical industry). For every case that went to deposition or trial, there have been $2-3$ that I have reviewed that were dropped or never heard from again.

Gregg H. Zoarski's Perspective. I first served as an expert witness in 1994, merely 2 years after completing my fellowship in neuroradiology. The trial that resulted was memorable for the courtroom drama that evolved when the jury foreman had a seizure during my testimony; both defendants moved for a retrial on the basis of bias that might have resulted from my rendering care to 
the foreman. The circumstances brought about a settlement the next morning.

Since 1994, I have served as an expert witness for both plaintiffs and defendants in numerous cases throughout the United States. Depositions are common; trial appearances are rather rare, occurring typically only once or perhaps twice a year. With the high cost of pursuing a medical negligence case to its resolution, it is not surprising that calls from "ambulance chasers" or other disreputable firms are nearly nonexistent. On the contrary, most plaintiffs and defense firms that have sought my opinion are looking for a truthful expert analysis and opinion regarding the issues of the case. Furthermore, it has struck me that most of the firms with which I have interacted view their clients' best interest and well-being as a priority.

Alexander S. Mark's Perspective. I have been contacted by attorneys on both sides of the case approximately 20 times in the past 20 years. Having initially practiced in a large tertiary care semiacademic hospital, I have also been named in 5 law suits during that time (as "collateral damage" when other physicians were sued). Fortunately, all these cases were dismissed. I am grateful to the experts hired by my attorneys in each case.

I view my role as an expert witness as one of public service, trying to strongly discourage any frivolous suit regardless of the damages sustained. I offer an opinion based on the findings of the studies provided in the clinical context at the time.

Erin S. Schwartz's Perspective. Assuming that the contact was related to the relative paucity of pediatric neuroradiologists, I was approached to serve as an expert witness immediately out of fellowship and continue to be sought out periodically. I have served as an expert witness approximately 50 times during almost 20 years.

\section{Testifying for Plaintiffs or Defendants Only?}

Many physicians are uncomfortable about testifying "against their brethren" as a plaintiff expert witness. However, the definition of "brethren" may be extended to neuroradiologists, radiologists in general, neuroscience clinicians, or all physicians. The survey of American Society of Neuroradiology members found that $69.7 \%$ (324 of 465) are willing to testify for both plaintiff and defendant firms, ${ }^{3}$ and most professional organizations encourage an egalitarian view of serving in the name of justice rather than on one side or the other. ${ }^{1,5}$ Others may restrict their expert witness testimony to physicians outside their geographic area to ensure that they do not alienate their referrers or compatriots at the state radiologic society.

Of the 50 cases for which I have served as a medical malpractice expert witness, I have testified on behalf of the plaintiff in 27 and the defendant in 23. Of the nonmedical malpractice cases, I have testified in 5 cases for the plaintiff and 5 for the defendant. It seems that most people who have negative attitudes about plaintiff malpractice expert witnesses believe they should be shunned. The nuance is that I never feel like I am testifying "for" or "against" anyone. I see myself as part of the investigative process, and I am testifying for the truth in the case. There are many cases in which a lawyer will ask my opinion, get it, say "thank you," and never talk to me again, asking me to return the materials. I am not offended, and if they find another person with a reasonable opposing opinion to mine, then that is part of the justice system.

Gregg H. Zoarski's Perspective. While limiting testimony to defense work only may simply result from a physician's heartfelt discomfort with testifying against another physician, such practice will certainly be exploited by the plaintiff's counsel in an attempt to discredit the witness. Whether plaintiff or defendant, the parties involved in a malpractice action should always have access to fair and unbiased analysis of the care that was rendered, as well as damages. Furthermore, a lack of readily available and unbiased experts could ultimately drive plaintiffs' attorneys to rely on a less impartial pool of experts, who might have a lower threshold for supporting claims regarding standard of care and causation (ie, "hired guns"). On the other hand, it is common for experts to decline plaintiffs' cases in which the defendants are in geographic or social proximity or likely to fall within their circle of practice. It is important to consider who you would want as a plaintiff's expert in a malpractice action in which you were a defendant. Ideally that would be someone with considerable experience and perspective in the issues involved, rather than a less-qualified individual. In many instances, including a multitude of matters in which I have been contacted to review a case from a plaintiff's attorney, the matter was not filed or, if already in suit, sometimes not pursued as a result of a qualified expert's opinion that there was not a breach in the standard of care and/or a lack of causation.

Alexander S. Mark's Perspective. I try to review the case without knowledge of which side the attorney is representing, even though this is not always easy because some lawyers only represent plaintiffs or vice versa. I do not exclude cases on the basis of which side is contacting me.

Erin S. Schwartz's Perspective. My experience has been similar to Dr Yousem's comments, including having been contacted by many attorneys to provide an "informal" opinion without being formally declared as their expert, and our contact was limited to that single interaction.

\section{Technique}

One of the reasons that I testify for both plaintiffs and defendants is that I do blinded reviews. This means that I do not know whether the law firm that contacts me is a plaintiff or defense firm. I usually ask that I review the cases with only the history provided to the radiologist on the referral slip at the time of the review. Quite often this elicits the response that there is no claim against the radiologist, but I still read the case blinded to the issues of the case. I give the reading verbally, and I do not take notes because these notes are "discoverable" by the attorneys and may not accurately reflect my opinions on the case. Sometimes the lawyers hear my interpretation and say, "Thank you. Send me your bill." Sometimes they say, "Thank you. Would you now like to hear the issues on the case?" Sometimes they say, "Thank you. Please send us a report in writing." Sometimes they say, "Actually, I am more interested in the paranasal sinuses than the brain." Sometimes they say, "Can you quantify the brain damages? We are consulting you for the damage assessment of the brain/spine/neck."

I have made it my modus operandi that if the legal firm, in 
their e-mail invitation to serve as an expert witness, gives background on the issues that their side wants addressed or other information that might bias me, I refer the case to another colleague. If they start to tell me something about the case on the phone, I usually say, "Stop. I'd prefer to read the case blinded to any information except what was provided to the radiologist at the time of the examination. After I give you my blinded interpretation, we can discuss the issues you want addressed. Just send me the images."

By having this policy in place, I can honestly say in deposition 3 years later (after I have forgotten everything about the case "between-hand") that I did a blinded review as per my convention.

Of course, this means that I may be contacted by plaintiff or defense teams without bias. Frankly, I do not remember whether a firm represents one or the other if they recontact me for a different case in the future. That is the benefit of having a poor memory for these things.

Gregg H. Zoarski's Perspective. Once contacted by a law firm, it is impossible to erase the knowledge that the matter under consideration is somehow related to litigation. Some will claim that this knowledge alone raises the level of scrutiny that an expert may dedicate to their review of the imaging and records. In a radiology matter, an expert for either side may assume the presence of a missed finding and search "harder" and longer" than they typically might in the usual clinical setting. The next level of bias can arise when an attorney relates the facts of the case, the outcomes, and his or her legal opinion to the expert during an initial conversation. Like Dr Yousem, I will always stop an attorney from telling me about a case (to avoid bias). I will then review the imaging studies and contact the attorney to discuss the findings or, at other times, record my findings on a dated memo with the note that my findings and opinions were based simply on review of the imaging and formulated before reviewing records or correspondence.

Alexander S. Mark's Perspective. Similar to Dr. Yousem, I also try to learn from other people's mistakes.

Erin S. Schwartz's Perspective. Similar to Dr. Yousem, my practice is to review the imaging studies without, or at least before, review of the medical records and formal radiologist interpretation. The imaging findings are the findings - and whether I am consulted by the defense or plaintiff teams does not impact my interpretation.

\section{Who Are the Defendants?}

Another assumption made is that when you are serving as an expert witness, you are testifying for or against your colleagues in radiology. That is not my experience at all. Of the 50 medical malpractice cases in which I have been deposed or testified in court, radiologists were named in the suit in only 14 (28\%). If one adds in the other 10 nonmalpractice cases, the 14 constitute $23.3 \%$ of my expert opinion volume. Of these 60 cases, I testified on the plaintiff's side in 9 cases $(15 \%)$ in which a radiologist was a defendant and in 5 cases $(8.3 \%)$ on behalf of a radiologist defendant.

Who are the most common nonradiologist defendants? Most were neurosurgeons (18/36), obstetricians (5/36), head and neck surgeons (5/36), and emergency department physicians (4/36).
Gregg H. Zoarski's Perspective. Most cases in which I have been involved have been matters of causation. In other words, what do the imaging studies show and are the findings related to the alleged injuries? Overall, the defendants in most cases that I have reviewed involve spine surgeons, neurologists, and emergency department physicians and are related to the outcome of spinal surgery, hypoxic brain injury, or a failure to diagnose and treat acute stroke in a timely fashion. While I may provide standard-of-care opinions in these matters, some states are restrictive with regard to the training and practice requirements to qualify as a standardof-care expert. I do review a number of cases that involve standard of care in radiology or neurointervention; however, these are perhaps approximately $25 \%$ of my volume. Those cases typically involve allegations of damages caused by a missed finding or improper performance of a neurovascular or spinal intervention. Many of those involve the failure to detect and report a brain aneurysm or related findings such as subarachnoid hemorrhage or a small intracranial or head and neck tumor.

Alexander S. Mark's Perspective. I prefer not to testify against colleagues in my community. If I think that malpractice has been committed, I mention it to the attorney and suggest that they find another expert. I strongly discourage pursuing a claim if I think it has no merit, regardless of the outcome. I have not always been successful, and on 1 occasion, I was hired 2 years later by the opposing party.

Erin S. Schwartz's Perspective. As a pediatric neuroradiologist, most cases on which I am asked to serve as an expert witness involve so called "bad baby" cases, in which the request of the radiology expert is to assist with confirmation that the pattern of brain injury is indeed that typically associated with hypoxic-ischemic injury and to suggest the time interval when the injury most likely occurred. More commonly, I am contacted by attorneys representing a hospital or an obstetrician/obstetrical group but have been retained by the plaintiff's attorneys as well. Rarely, I have served as an expert in criminal matters, relating to abusive head trauma. Only once have I been asked by attorneys representing a radiologist to determine whether the radiology interpretation of a scan met the standard of care, and that was regarding the interpretation of a fetal brain MR imaging though I suspect I will be seeing more of these as use of fetal MR imaging proliferates.

\section{What Type of Cases Are Involved?}

When separating the cases into brain, spine, and head and neck, one finds that most $(n=28)$ are from the brain followed by the spine $(n=15)$ and the head and neck $(n=7)$. Of the brain cases, most were related to hypoxic-ischemic events $(n=11)$ and missed hemorrhages $(n=10)$. The spine cases were dominated by the results of and complications after surgery for degenerative disease $(n=11)$. In fact, of the 50 cases, many were related to surgical procedures $(n=14)$.

Of the 14 cases in which radiologists were named, 3 involved delayed diagnosis of aneurysm or subarachnoid hemorrhage and 2 involved delayed diagnosis of stroke. The remaining 9 cases did not have a theme.

Alexander S. Mark's Perspective. I have not participated in enough cases across the years to be able to come up with mean- 
ingful statistical trends. The cases range from missed tumors, optic neuritis, and other miscellaneous conditions.

Erin S. Schwartz's Perspective. The overwhelming majority of my cases are related to the suspicion of perinatal hypoxic-ischemic injury; rarely, cases have involved perinatal spinal cord injury, alleged wrong-site brain surgery, and trauma.

\section{Outcome of the Cases}

As an expert witness, you are often not privy to the outcome of cases in which you provide an opinion, even those in which you are deposed. Often the cases are settled, but the settlement agreement prohibits disclosure of the sum of money exchanged. Additionally, the defense team will often settle a case for a low amount of money and call it a "win" because of avoidance of court costs. In some states (eg, California), if the amount settled is less than $\$ 30,000$, the report is not counted as a settlement against the individual physician as part of the accumulated totals that result in public disclosure. Thus, it is difficult to determine "winners" except in cases that go to trial. For the 15 cases in which I testified at trial, 6 were plaintiff verdicts, 7 were defendant verdicts, and 2 were declared mistrials and subsequently settled out of court.

Of course, for every case that goes to deposition or trial there are, on average in my estimation, 3-4 that never come to that in part because they are determined to be frivolous (by the plaintiffs' lawyers) or are dropped (on behalf of the defendants) or are settled beforehand because the issues are so obvious.

Gregg H. Zoarski's Perspective. It is my experience that matters that I have reviewed for the plaintiff are much more likely to proceed to deposition than defense matters, which are frequently resolved before or early along the discovery timeline. Approximately one-half of the plaintiffs' matters I have reviewed have gone to deposition. This is certainly because claims are researched and reviewed internally by good plaintiff firms, which typically employ paralegals and nurses specifically for that purpose, before reaching out to expert witnesses. Moreover, the need for a witness with particular expertise may not even be evident before the initiation of discovery. Defense firms, on the other hand, tend to be reactive and will often designate an expert witness as soon as possible after receiving a claim or even on receiving notice of a pending claim. Some defense claims that I review are not yet even in suit. Often a defense matter is resolved via settlement before my deposition, particularly when a legitimate standard-of-care claim is raised by the plaintiffs, causation is clear, and the only matter at issue is the amount of damages.

Alexander S. Mark's Perspective. I agree with Dr Yousem. I do not always receive follow-up, and the results may be covered by confidentiality agreements. Most of the time, I felt that my testimony contributed to providing a balanced perspective on the case. Only a very small number of cases end up in a trial. Most are settled.

Erin S. Schwartz's Perspective. In my experience, approximately 1 in every 10-20 cases reaches deposition and even fewer go to trial, typically due to cases settling, and I am not notified of the outcome.

\section{DISCUSSION}

Although most radiology societies and the American Medical Association advocate for physicians to perform expert witness review, like peer review for quality improvement, in an unbiased objective manner, there is a stigma associated with engaging in medicolegal testimony. This is particularly true under several conditions: 1) only serving on one side or the other, refusing to testifying on behalf (usually) of plaintiffs or defendants ("hired guns"); 2) advertising one's services blatantly; 3 ) gouging the law firms/insurance companies with exorbitant fees; 4) taking positions at odds with convention; and 5) deriving a large proportion of one's income from experts' fees. Case law has established that it is reasonable for lawyers to receive information from experts on the following: 1) the percentage of gross income derived from expert witness testimony, 2) the cases in which they have testified in the previous 5 years in a manner that counsel can find such testimony in court documents, and 3) the name of the insurance company for testimony in personal injury cases in the previous 10 years. ${ }^{6,7}$ Most law firms prefer an expert who is actively engaged in the practice for which they are opining. In fact, some jurisdictions look askance at experts that show income from testimony that exceeds $30 \%$ of their annual total compensation. "Professional experts" who are no longer in the practice of medicine but who are available for medicolegal testimony may be challenged if they are not up-to-date on the standard of care currently practiced (or at the time of the incident occurrence).

Most expert witnesses will say that they find medicolegal testimony a learning experience. This derives from several factors: 1 ) identifying one's own blind spots; 2) learning some medicine beyond radiology through the issues discussed by the clinical experts; 3) understanding the litigation process, especially how slowly it moves through the system; 4) understanding how often cases are settled even if duty, breach of standard of care, causation, and damages are not firmly established because of the expense of litigating a case; and 5) learning how to use the correct terms so as to best portray your opinions. On the latter point, malpractice cases are civil cases in which the legal teams must show that the preponderance of evidence supports their claims. In that regard, the medicolegal expert is expected to testify at a level of "more likely than not." Therefore, one does not have to be absolutely certain that the mass is a tumor rather than an aneurysm: One merely has to believe that given the evidence, it is more likely to be a neoplasm. That assuredness is not necessarily how we practice medicine. We want to be $99 \%$ sure that we do not send a neurosurgeon in to biopsy a mass and find that it is an aneurysm.

The other epiphany one experiences as an expert witness is the dangers that other professions face in practicing medicine: knowing when to deliver a fetus in distress, whether to operate on someone who already has a myelomalacic spinal cord, which studies are absolutely needed before intervening on vascular cases, and how rapidly an emergency department patient must be triaged and treated. These are sometimes decisions that determine a good outcome versus a "negligence" case. The neuroradiology expert may be testifying on the extent of CNS injury in such cases, but seeing how precarious the situation may be when clinicians are making judgments in the practice of medicine can be eye-opening. 
One also sees that there are just as many cases that are absolutely egregious as frivolous. The frivolous ones, because of the cost of litigation, often are dropped quickly. The egregious ones often proceed to court because the potential financial rewards to the plaintiff may be dramatic when presented to a jury. Most cases brought to trial have definite justification, and the expert witness is the key to enlightening the jury about the complex medical issues.

\section{Final Comments}

Gregg H. Zoarski's Perspective. Beyond developing an opinion regarding the issues of standard of care, causation, and damages as any particular matter may require, an expert witness assumes a valuable role as a teacher. The "class" includes attorneys on both sides of the matter as well as the parties and perhaps even other experts reviewing the matter. Maintaining this role avoids advocating for either the plaintiff or defense, and ultimately, if the matter proceeds to trial, the judge and jury join the classroom and rely on the education you provide to reach some very important decisions.

Alexander S. Mark's Perspective. I have found that the lawyers who consult me as an expert witness will usually follow my advice and not pursue frivolous lawsuits even when something was missed, as long as it did not result in an injury or if it did not change the outcome.

Erin S. Schwartz's Perspective. When called on to provide expertise regarding the neuroimaging features in pediatric patients, expert witnesses would do well to remember that the brains of premature and full-term infants are not simply small adult brains and that the findings in perinatal hypoxic-ischemic injury do not necessarily have the same etiologies or follow the same temporal and imaging evolution as those from arterial thrombosis or embolism in older children and adults. Our opinions must be evidencebased and consistent, regardless of who hires us.

Disclosures: David M. Yousem—UNRELATED: Expert Testimony: medicolegal work; Payment for Lectures Including Service on Speakers Bureaus: ACR Education Center; Royalties: Elsevier for 5 books; Travel/Accommodations/Meeting Expenses Unrelated to Activities Listed: Radiological Society of North America 2018 as an awardee. Gregg H. Zoarski-UNRELATED: Expert Testimony: various, Comments: none specifically on behalf of medical product or pharmaceutical manufacturers. Erin S. Schwartz-UNRELATED: Expert Testimony: numerous legal firms.

\section{REFERENCES}

1. ACR Practice Parameter on the Physician Expert Witness in Radiology and Radiation Oncology. https://www.acr.org/-/media/ACR/Files/ Practice-Parameters/ExpertWitness.pdf. Accessed April 17, 2018

2. ACR Expert Witness Affirmation Statement. http://appcenter.acr.org/ ewa/(S(w0eqgug5hlj2tkcduhojy2c4))/default.aspx?ewa=true. Accessed April 17, 2018

3. Pereira NP, Lewin JS, Yousem KP, et al. Expert witnesses: neuroradiologists' perspectives. J Am Coll Radiol 2014;11:984-88 CrossRef Medline

4. Pereira NP, Lewin JS, Yousem KP, et al. Attitudes about medical malpractice: an American Society of Neuroradiology survey. AJNR Am J Neuroradiol 2014;35:638-43 CrossRef Medline

5. AMA. Code of Medical Ethics Opinion 9.7.1. https://www.amaassn.org/delivering-care/medical-testimony. Accessed April 17, 2018

6. Behler v. Hanlon, 199 F.R.D. 553 (D. Md. 2001)

7. Gutheil TG, Simon RI, Simpson S. Attorneys' requests for complete tax records from opposing expert witnesses: some approaches to the problem. J Am Acad Psychiatry Law 2006;34:518-22 Medline 